\title{
Prevention of acute gastric erosions in the rat by novel semi-synthetic amphipathic analogues of pepstatin
}

\author{
S P J HUDDY, G PATEL, G C HEYWOOD, B M AUSTEN, \\ AND J HERMON-TAYLOR
}

From the Department of Surgery, St George's Hospital Medical School, London

Summary Pepstatin is a potent aspartyl proteinase inhibitor which is virtually insoluble in physiological media. Five semi-synthetic amphipathic analogues of pepstatin, prepared by $\mathbf{N}$ terminal substitution of native pepstatin with hydrophilic oligopeptides, have been assessed for their ability to protect the mucosa in two animal models of acute gastric erosions. Concentrations of approximately $90 \mathrm{pmol} / \mathrm{mg}$ were acheived in the rat gastric mucosa after oral administration of a 20 mmol solution. These levels are theoretically adequate to inhibit all pepsin like proteinase activity (including zymogens). Each pepstatin analogue was tested by intragastric administration in a controlled hypotension/luminal acid animal model of acute gastric erosions in a group of six animals. All the inhibitors tested produced marked mucosal protection, as measured by a mucosal damage index, compared with control animals (control mean 241, range 100-420; Pepstatinyl-Gly-OrnOrn-Cys (10 mmol) mean 3, range 0-8, p<0.01; Pepstatinyl-Gly-Cysteic acid-Cysteic acid (10 mmol) mean 5, range 0-21, p<0.01; Pepstatinyl-Gly-Lys-Lys (10 mmol) mean 18, range 0-60, p<0.01; Pepstatinyl-Gly-Cysteic acid-Cysteic acid (1 mmol) mean 24, range 0-86, $p<0 \cdot 01$; Pepstatinyl-Gly-Orn-Orn-Cys (1 mmol) mean 57, range 0-116, p<0.01; Pepstatinyl-Gly-Asp-Asp $(1 \mathrm{mg} / \mathrm{ml}$ suspension) mean 68, range 19-126, $\mathrm{p}<0 \cdot 01$; Pepstatinyl-Arg-OMe (1 mmol) mean 93, range 4-142, p<0.05, Pepstatinyl-Gly-Lys-Lys (1 mmol) mean 157, range 70-286, NS). In a platelet activating factor $/ 20 \%$ luminal ethanol model of erosions the pepstatin analogues again provided mucosal protection although this only reached statistical significance for one of three compounds tested.

Acute gastric erosions are lethal complications which occur in a range of severe medical illness, ${ }^{1-3}$ after trauma or surgery, ${ }^{45}$ as a sequel to neurological lesions $s^{a-8}$ or in association with burns. ${ }^{9-11}$ The advent of $\mathrm{H}_{2}$ antagonists does not appear to have abolished this problem, probably because of a failure to reliably raise the $\mathrm{pH}$ above the critical level of $3 \cdot 5 \cdot{ }^{12-14}$

There is now extensive evidence to implicate pepsin in the production of the acute gastric erosions. ${ }^{15-17}$ It has been suggested that erosions may be produced as a result of the inappropriate intramucosal activation of pepsinogen initiated by a fall in mucosal $\mathrm{pH}^{18-21}$ Effective inhibition of mucosal pepsin may therefore provide a pharmacological

Address for correspondence: Mr S P J Huddy, Dept of Surgery, St George's Hospital Medical School, Cranmer Terrace, London SW17 0RE.

Received for publication 1 June 1988 means of abolishing or limiting the mucosal damage produced in those circumstances where acute gastric erosions occur.

Amylopectin sulphate (SN-263) (a pepsin inhibitor) has been shown to protect against ulceration in pylorus ligated rats or induced by daily steroid administration. ${ }^{22}$ Another weak pepsin inhibitor, degraded carrageenin, has been shown to protect guinea pigs against steroid administration. ${ }^{23}$ Amylopectin sulphate has accelerated the healing of chronic gastric ulcers ${ }^{24}$ but a double blind clinical trial has failed to show any benefit from its use on the symptoms produced by duodenal ulceration. ${ }^{25}$

Pepstatin, an oligopeptide produced by bacteria, is an extremely potent inhibitor of aspartyl proteinases. When first isolated it was shown to have a protective effect against rumenal ulceration in pylorus ligated rats. ${ }^{26}$ It did not, however, protect against acute gastric erosions produced in a control- 
led hypotension/luminal acid animal model ${ }^{21}$ and Bonnevie et al have failed to show any benefit from this compound in a double blind clinical trial of the healing of chronic duodenal ulcers in man. ${ }^{27}$ This is likely to be because of the almost total insolubility of pepstatin in aqueous physiological solvents. This is responsible for its lack of absorbtion from the gastrointestinal tract. ${ }^{28}$ Ford and colleagues have shown that luminal pepstatin will not prevent the development of acute gastric erosions in a controlled hypotension/luminal acid rat model despite inhibition of more than $90 \%$ of luminal proteinase activity. ${ }^{21}$

\section{Methods}

PEPSTATIN ANALOGUES

We have synthesised a range of semi-synthetic analogues of pepstatin, a potent inhibitor of pepsin produced by bacteria, by the coupling of short hydrophilic peptides to the $\mathrm{N}$ terminus of pepstatin. The methods of synthesis and the in vitro testing of these compounds is being published elsewhere (Huddy $e t$ al, in preparation). Briefly, the solubility of the inhibitors was determined at both $\mathrm{pH} 2$ and $\mathrm{pH}$ 5.3 by lyophilisation to constant weight of a saturated solution of the inhibitor. The Ki (dissociation constant of the enzyme/inhibitor complex, thus the lower the value the more potent the inhibitor) was measured by assaying the activity of known quantities of pepsin A against casein after preincubation of the pepsin with the pepstatin analogues. The hydrolysis products of casein were assayed by a fluorometric method. The $\mathrm{IC}_{50}$ was derived graphically from which the $\mathrm{Ki}$ was calculated. The solubilities and $\mathrm{Ki}$ values are listed in the Table.

Six compounds are used in this series of experiments, Pepstatinyl-Gly-Lys-Lys, Pepstatinyl-GlyOrn-Orn-Cys, Pepstatinyl-Gly-Cysteic acid-Cysteic acid, Pepstatinyl-Gly-Arg-OMe $\quad(\mathrm{OMe}=$ methyl ester), Pepstatinyl-Arg-OMe and Pepstatinyl-GlyAsp-Asp. A radio active marker in the form of tritiated glycine was incorporated into each molecule. These compounds all have significantly better aqueous solubility than native pepstatin whilst retaining a similar potency of inhibition against porcein pepsin. The compounds were tested in vivo in two different rat animal models of acute gastric erosions, a controlled hypotension/luminal acid model and a platelet activating factor (PAF)/luminal $20 \%$ ethanol model.

MEASUREMENT OF TISSUE INHIBITOR

CONCENTRATIONS

Male wistar rats (200-250 g) were obtained from the Biological Research Facilities situated at St George's
Table Solubility in distilled water or dilute $\mathrm{HCl}$ and the $\mathrm{Ki}$ values obtained for pepstatin and the semi-synthetic pepstatin analogues at $\mathrm{pH} 5 \cdot 2$ and $\mathrm{pH} 2$

\begin{tabular}{|c|c|c|c|c|}
\hline \multirow[b]{2}{*}{ Inhibitor } & \multicolumn{2}{|c|}{$\begin{array}{l}\text { Solubility } \\
(\mathrm{mg} / \mathrm{ml} \text { solution })\end{array}$} & \multicolumn{2}{|c|}{$\begin{array}{l}K i \\
\left(M \times 10^{\prime \prime}\right)\end{array}$} \\
\hline & pH $5 \cdot 3$ & pH 2 & pH $5 \cdot 3$ & $p H 2$ \\
\hline Pepstatin & 0.08 & 0.09 & $10 \cdot 8$ & $1 \cdot 4$ \\
\hline Pepstatinyl-Gly-Lys-Lys & 49 & 51 & $15 \cdot 3$ & $2 \cdot 9$ \\
\hline Pepstatinyl-Gly-Orn-Orn-Cys & 31 & 38 & $9 \cdot 3$ & $2 \cdot 2$ \\
\hline Pepstatinyl-Gly-Arg-OMe & $1 \cdot 6$ & $1 \cdot 6$ & $10 \cdot 3$ & $1 \cdot 1$ \\
\hline $\begin{array}{l}\text { Pepstatinyl-Gly-Cysteic acid- } \\
\text { Cysteic acid }\end{array}$ & 131 & 137 & $17 \cdot 8$ & $5 \cdot 5$ \\
\hline Pepstatinyl-Gly-Asp-Asp & $1 \cdot 2$ & $0 \cdot 8$ & $30 \cdot 4$ & $8 \cdot 3$ \\
\hline
\end{tabular}

Hospital one week before the experiments. They were starved for 18 hours before the study during which time they were housed in wire bottomed cages and allowed free access to water. Anaesthesia was induced by intraperitoneal sodium pentobarbitone (Sagatal, $60 \mathrm{mg} / \mathrm{kg}$ ) and supplemented by further intraperitoneal anaesthetic as required during the procedure.

A laparotomy was carried out and the pylorus ligated taking great care to avoid damage to the blood supply. The oesophagus was temporarily occluded by a silk sling whilst $1 \mathrm{ml}$ of test solution was injected into the stomach with a fine needle through the rumenal portion of the stomach wall. The bladder was then emptied of urine.

The test solution comprised either $0.5 \mathrm{ml}$ of a 20 $\mathrm{mM}$ solution of ${ }^{3} \mathrm{H}$ labelled inhibitor (PepstatinylGly-Lys-Lys, Pepstatinyl-Gly-Orn-Orn-Cys or Pepstatinyl-Gly-Cysteic acid-Cysteic acid) or $1 \mathrm{ml}$ of a suspension containing 1 umol of Pepstatinyl-GlyAsp-Asp (due to this compound's limited solubility).

After 90 minutes a cannula was introduced transduodenally into the bile duct and bile collected over a further 30 minutes The animal was then killed. The viscera were removed taking the stomach last to prevent contamination. The stomach was twice rinsed in a stream of running water and blotted dry.

The mucosal surface of the stomach was gently scraped with a blunt spatula to remove mucus which was collected and weighed. The stomach was then again rinsed in a stream of cold water and blotted dry. A biopsy of mucosa was taken by dissection in the plane between mucosa and muscle. A piece of stomach muscle was then taken from an adjacent area. A small biopsy (around $60 \mathrm{mg}$ ) was taken from the liver, kidney and lung and a larger biopsy from the skeletal muscle. Each biopsy was weighed and homogenised in $1 \mathrm{ml} 2 \%$ sodium dodecylsulphate (SDS) with a Teflon pestle machined to fit a plastic test tube. The tubes were covered with silver foil to prevent evaporation and incubated in a boiling 
water bath for 10 minutes to complete cell lysis. The samples were then centrifuged at $8000 \mathrm{~g}$ for four minutes and $0.5 \mathrm{ml}$ aliquots of the supernatant added to $10 \mathrm{mls}$ of PCS scintillant. Samples of blood, urine and bile were simply centrifuged and aliquots of supernatant added to scintillant before counting. The results were corrected for quenching. The tissue concentrations of each pepstatin analogue were calculated and the results expressed as $\mathrm{pmol} / \mathrm{mg}$ wet weight of tissue.

\section{CONTROLLED HYPOTENSION/LUMINALACID} MODEL

Male Wistar rats were obtained and anaesthetised as above. The right femoral artery was cannulated with a $22 \mathrm{G}$ 'Medicut' cannula connected to a pressure transducer which allowed continuous monitoring of the arterial blood pressure. The right femoral vein was cannulated with a $3 \mathrm{~F}$ gauge polyethylene cannula and the animal was then heparinised with $0.05 \mathrm{ml}$ of $1000 \mathrm{IU} / \mathrm{ml}$ heparin.

The pylorus was ligated as in the previous experiments and the test solution introduced into the stomach by a fine needle through the rumenal portion.

Immediately after the administration of the test solution blood was withdrawn through the venous line into a $20 \mathrm{ml}$ syringe until the systolic pressure was reduced to between 20 and $30 \mathrm{mmHg}$. Further blood was withdrawn or retransfused over the next two hours in order to maintain the systolic pressure at this level. At the end of this period the blood remaining in the syringe was retransfused over one minute and after a further 10 minutes the animal was killed.

The stomach was immediately removed and examined both by naked eye and under the operating microscope to assess the degree of mucosal damage. Representative samples of the stomachs were fixed in formal saline, sectioned, stained with haematoxylin and eosin and subjected to histological examination.

The number of erosions in each stomach were counted and one point was awarded for each erosion. The area of each erosion greater than $1 \mathrm{~mm}^{2}$ was then estimated using a millimetre scale and a further point awarded for each additional $\mathrm{mm}^{2}$ was added. The grand total of points constituted the erosion index (EI). When the pepstatin analogues were administered at lower concentrations a new form of damage was observed, which will be described subsequently. This necessitated the development of a different scoring system. Here each area of mucosal damage was graded. (1) Just visible dusky patch, (2) a distinct grey or purple patch within the mucosa, (3) a black almost necrotic area, and (4) a true erosion. The total area in $\mathrm{mm}^{2}$ of each grade of mucosal damage was estimated using the millimetre scale and the value multiplied by the grade of the damage. The totals were then added together to produce the mucosal damage index (MDI).

Five pepstatin analogues were assessed in this animal model Pepstatinyl-Gly-Lys-Lys, PepstatinylGly-Orn-Orn-Cys, Pepstatinyl-Gly-Cysteic acidCysteic acid Pepstatinyl-Gly-Asp-Asp and Pepstatinyl-Gly-Arg-OMe. The test solutions were all made up in $100 \mathrm{mM} \mathrm{HCl}$ to a volume of $1 \mathrm{ml}$. The control animals received $\mathrm{HCl}$ alone. The pepstatin analogues were tested at $10 \mathrm{mM}$ (if sufficiently soluble) and $1 \mathrm{mM}$ concentrations, with the exception of Pepstatinyl-Gly-Asp-Asp which was administered as a suspension of $1 \mathrm{mg} / \mathrm{ml}(0.97 \mu \mathrm{mol} / \mathrm{ml})$ because of the limited solubility $(0.8 \mathrm{mg} / \mathrm{ml})$ in aqueous solution at this $\mathrm{pH}$. The addition of the inhibitor did not produce a detectable change in the $\mathrm{pH}$ of the $\mathrm{HCl}$. Each group consisted of six animals. The test solutions were all administered to the animals in a blind fashion and the code was only broken after the conclusion of the experiments and calculation of the damage scores.

PAF/LUMINAL $20 \%$ ETHANOL MODEL

The animal model used was similar to that described by Rosam et al..$^{29}$ Male wistar rats (200-250 g) were obtained, starved and anaesthetised as described above and the femoral vessels again cannulated but the animal was not heparinised.

The stomach was isolated and the test solution injected through the rumenal portion. PAF $(50 \mathrm{ng} /$ $\mathrm{kg} / \mathrm{min}$ ) in normal saline containing $0.25 \%$ bovine serum albumin was infused via the femoral venous line for 10 minutes. The animal was then allowed to recover for 30 minutes before being killed. The stomach was removed and the erosions scored according to the erosion index. Representative stomachs were subjected to histological examination.

In this model the test solutions were made up in $20 \%$ ethanol and the final volume was again $1 \mathrm{ml}$. Three inhibitors were tested in this model Pepstatinyl-Gly-Orn-Orn-Cys, Pepstatinyl-GlyCysteic acid-Cysteic acid and Pepstatinyl-Gly-AspAsp. The first two were administered as a $10 \mathrm{mM}$ solution and the third as a suspension of $10 \mathrm{mg}$ in $1 \mathrm{ml}$ $(9.7 \mu \mathrm{mol} / \mathrm{ml})$ because of the limited solubility $(2.9$ $\mathrm{mg} / \mathrm{ml}$ ) in $20 \%$ ethanol. Each group again consisted of six animals.

\section{STATISTICAL ANALYSIS}

A reduction of the EI or MDI of the pepstatin analogue treated groups compared with the control animals was tested for statistical significance by the single tailed Mann Witney U test. 

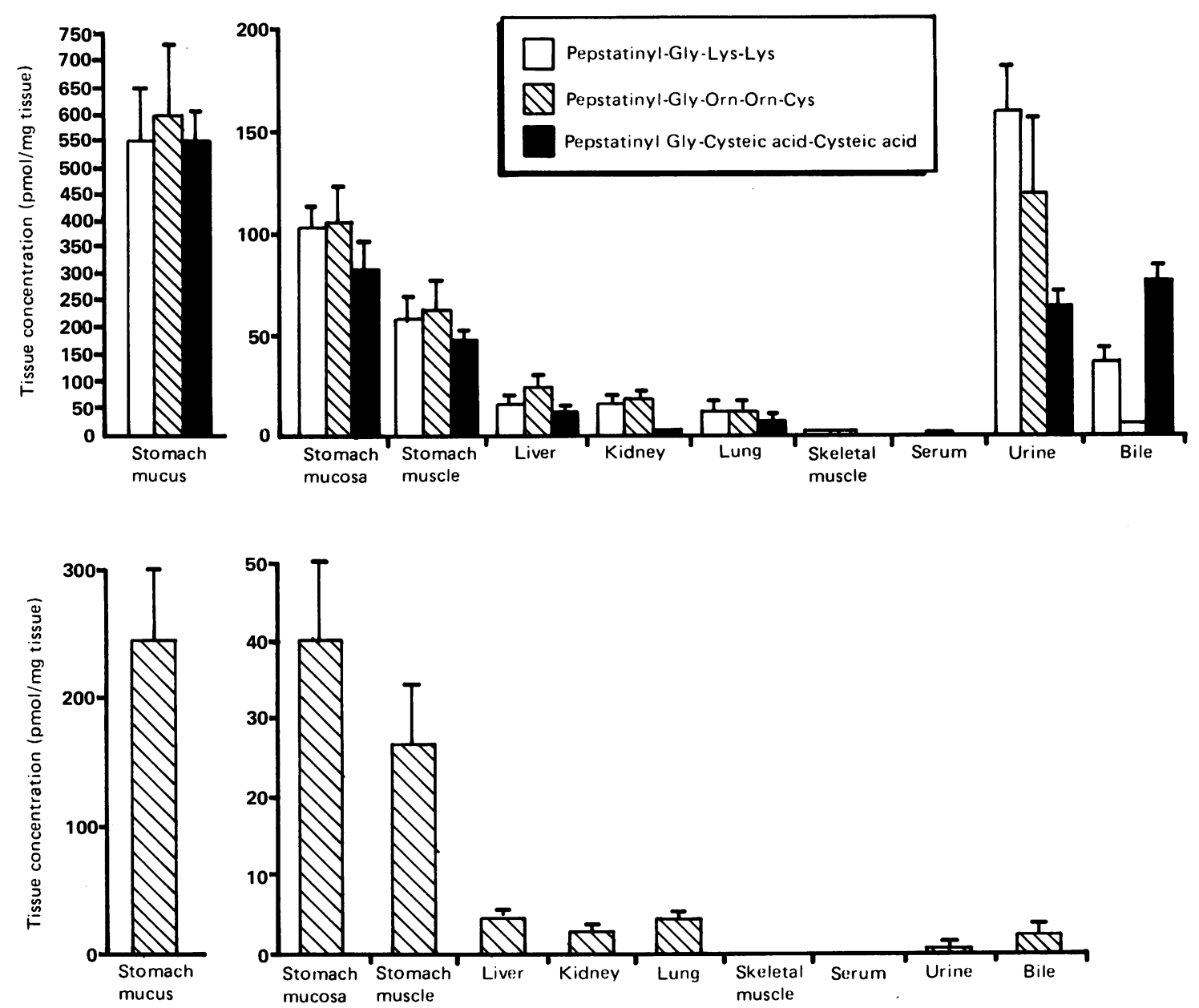

Figs 1 ( $a$ and b) Tissue concentrations achieved two hours after the intragastric administration of a $20 \mathrm{mM}$ solution of either pepstatinyl-Gly-Lys-Lys, Pepstatinyl-Gly-Orn-Orn-Cys or Pepstatinyl-Gly-Cysteic acid-Cysteic acid (a) or a suspension containing 1 umol/ml Pepstatinyl-Gly-Asp-Asp (b).

\section{Results}

\section{TISSUE CONCENTRATIONS}

The tissue concentrations achieved two hours after intragastric administration of the pepstatin analogues are shown in Figures 1a and $b$. The three inhibitors administered at $20 \mathrm{mmol}$ all produce a similar pattern of tissue distribution but differ in the proportions excreted in bile or urine. Pepstatinyl-Gly-Lys-Lys and Pepstatinyl-Gly-Orn-Orn-Cys are predominantly excreted in urine, whilst the majority of Pepstatinyl-Gly-Cysteic acid-Cysteic acid is excreted in bile. They each produce a gastric mucus concentration of around $550 \mathrm{pmol} / \mathrm{mg}$ wet weight of tissue and a gastric mucosal concentration of around $90 \mathrm{pmol} / \mathrm{mg}$ wet weight of tissue. Pepstatinyl-Gly-Asp-Asp when administered as a suspension of $1 \mu \mathrm{mol}$ in $1 \mathrm{ml}$ (maximum solubility approx $0.8 \mathrm{mmol}$ ) produced a mucus concentration of $246 \mathrm{pmol} / \mathrm{mg}$ wet weight of tissue and a mucosal concentration of $41 \mathrm{pmol} / \mathrm{mg}$ wet weight of tissue.

\section{CONTROLLED HYPOTENSION/LUMINAL ACID}

\section{MODEL}

In the control group all of the animals developed acute gastric erosions. There was usually altered blood present in the stomach on opening the specimen at the end of the experiment. The lesions were dusky red or light brown. They tended to be most extensive in the body immediately distal to the 
junction with the rumenal portion and were not seen in the rumen or antral portions of the stomach. Erosions were most prominent on the crests of the rugal folds. They appeared as single spots or coalesced to form long streaks of mucosal damage. When examined under the operating microscope these lesions could be clearly seen to be breaches in the mucosa. The histology revealed widespread areas of superficial necrosis with focal areas in which there was more extensive damage. Here there was necrosis, and haemorrhage extending deep into the gastric mucosa sometimes reaching the muscularis mucosae. Haemorrhage is prominent in these deeper lesions which correspond to the macroscopically visible acute gastric erosions.

The mean erosion index of the control group of six animals was $60 \cdot 2$ (range $25-105$ ). In the three groups of animals which received $10 \mathrm{mM}$ pepstatin analogue at the $10 \mathrm{mM}$ concentration there were no acute gastric erosions in any animal. The only observed macroscopical difference from the control animals was a slight thickening of the mucosa and a patchy distribution of the mucus layer in the treated animals. Microscopically there was minimal loss of the surface of the mucosa and an occasional intramucosal lesion as described below.

When the inhibitors were administered at the $1 \mathrm{mM}$ concentration a new pattern of mucosal damage was seen. In addition to a few true acute gastric erosions there were areas of mucosa, which were occasionally extensive, and which appeared as discoloured patches. These ranged from just visible dusky lesions to areas where the mucosa had the appearance of being almost necrotic. These lesions differed from true erosions in that the surface contour of the mucosa appeared to be intact. They had the macroscopical appearance of intramucosal haemorrhages. The distribution of these lesions was very similar to that of the true acute gastric erosions in the control animals. The histology of these stomachs showed areas of superficial mucosal necrosis which in places appeared to have separated from the apparently normal underlying mucosa. The discoloured areas were seen to consist of discrete intramucosal areas of necrosis surrounding an intramucosal haemorrhage. The histological features of these were very similar to those of a true superficial erosion. The smallest of these lesions were found in the deepest parts of the mucosa. Lesions of increasing size extended further towards the surface but always involving the deeper layers. Around the largest lesions there was only a thin rim of intact mucosa covering the necrotic haemorrhagic area.

The MDI was devised to score the mucosal damage. This scoring system was felt to be justified for the following reasons. First, examination of the area surrounding these haemorrhages showed them to have the same histological features as the true superficial erosions. The presence of the entrapped haemorrhage increased their size and tended to overrather than under-estimate the severity of the lesion. Thus if anything the MDI will err on the side of conservatism in assessing any beneficial effect of the pepstatin analogues. Second, the pale lesions were shown to be small and deeply sited within the mucosa. As the lesions increased in size they extended further towards the mucosal surface but always involving the deeper layers. These progressively larger lesions appeared macroscopically as the darker areas. Third, the distribution of the intramucosal lesions within the stomach mirrors that of true erosions and finally, when true erosions were seen in the treated animals these were always associated with extensive areas of intramucosal damage. The theoretical basis for the MDI is discussed in more detail elsewhere. ${ }^{30}$

All the inhibitors tested at the $1 \mathrm{mM}$ concentration in the controlled hypotension/luminal acid model produced a reduction in the mucosal damage index compared to control animals. The reduction was significant for four inhibitors. The $p$ value for Pepstatinyl-Gly-Orn-Orn-Cys, Pepstatinyl-GlyCysteic acid-Cysteic acid and Pepstatinyl-Gly-AspAsp was $<0.01$ and for Pepstatinyl-Gly-Arg-OMe was $<0 \cdot 05$. There was a further reduction in the MDI when the concentration, of the three inhibitors which were sufficiently soluble, was increased to $10 \mathrm{mM}$. The MDI of each test group of animals is compared with that of the control animals in Figure 2.

PAF/LUMINAL $20 \%$ ETHANOL MODEL

The control animals that received an infusion of $50 \mathrm{ng}$ $\mathrm{PAF} / \mathrm{kg} / \mathrm{min}$ in the presence of luminal $20 \%$ ethanol all developed mucosal erosions. The mean erosion index of this group was 42 (range 17-64). The erosions appeared macroscopically similar to those produced in the controlled hypotension/luminal acid model although the lesions tended to coalesce rather more than in the previous model. The lesions were again found predominantly in the proximal body of the stomach and on the crests of rugal folds. There was complete antral sparing as in the previous model.

Platelet activating factor infused at the same rate but in the absence of the intragastric alcohol failed to provide a sufficiently consistent degree of mucosal damage to allow assessment of any potential benefit from the concurrent administration of the pepstatin analogues.

The histological appearance of stomachs from the control group of animals showed extensive surface necrosis and in places separation of this necrotic layer. In some areas the necrosis extends deeper into 


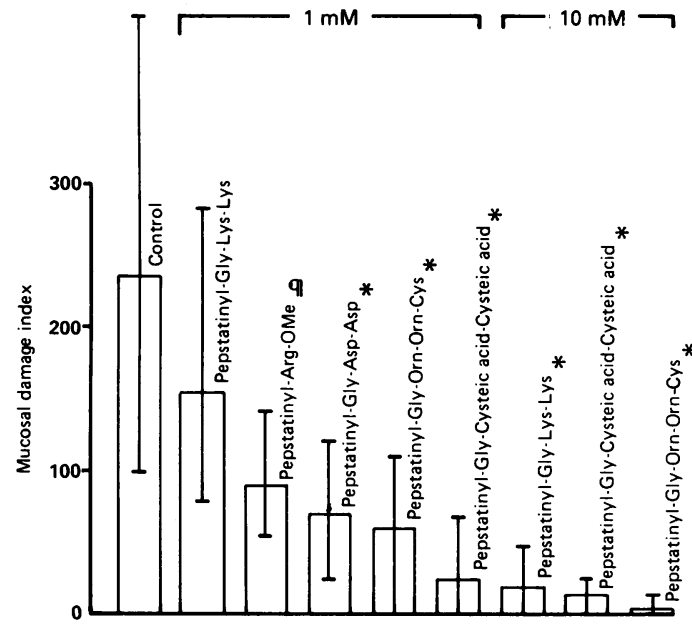

Fig. 2 Mucosal damage index (mean) of groups of six rats subjected to controlled hypotension in the presence of intragastric $100 \mathrm{mM} \mathrm{HCl} \mathrm{either} \mathrm{alone} \mathrm{or} \mathrm{containing} \mathrm{dissolved}$ pepstatin analogue. Bars indicate the range of values obtained $\left(\mathbb{\|}-p<0.05 \mathrm{v}\right.$ control, ${ }^{*}-p<0.01 \mathrm{v}$ control).

the mucosa. The appearance of these lesions was similar to that found in the controlled hypotension/ luminal acid animal model although after PAF, the surface damage appears more extensive and diffuse, and the deeper lesions appeared less discrete.

All the inhibitors tested in this animal model (at the $10 \mathrm{mM}$ concentration) produced a reduction in the erosion index although only for Pepstatinyl-GlyCysteic acid-Cysteic acid did this achieve statistical significance $(\mathrm{p}<0.05)$ (Fig. 3). The lesions seen were all typical superficial erosions. There were no intramucosal haemorrhages, of the type seen when inhibitors were given at lower concentrations in the controlled hypotension/luminal acid animal model, either macroscopically or microscopically.

\section{Discussion}

A range of semi-synthetic analogues of pepstatin were synthesised with the intention of increasing the aqueous solubility whilst retaining the inhibitory potency of native pepstatin. This increase in aqueous solubility was intended to allow the achievement of mucosal concentrations which would be adequate to inhibit any active pepsin produced by the inappropriate intramucosal activation of pepsinogens within the gastric mucosa. The molecular modifications involved the coupling of a charged hydrophilic oligopeptide to the carboxyl terminus of pepstatin.

A number of features were included within the substituent oligopeptide which might confer potentially useful properties to the compound. Two com-

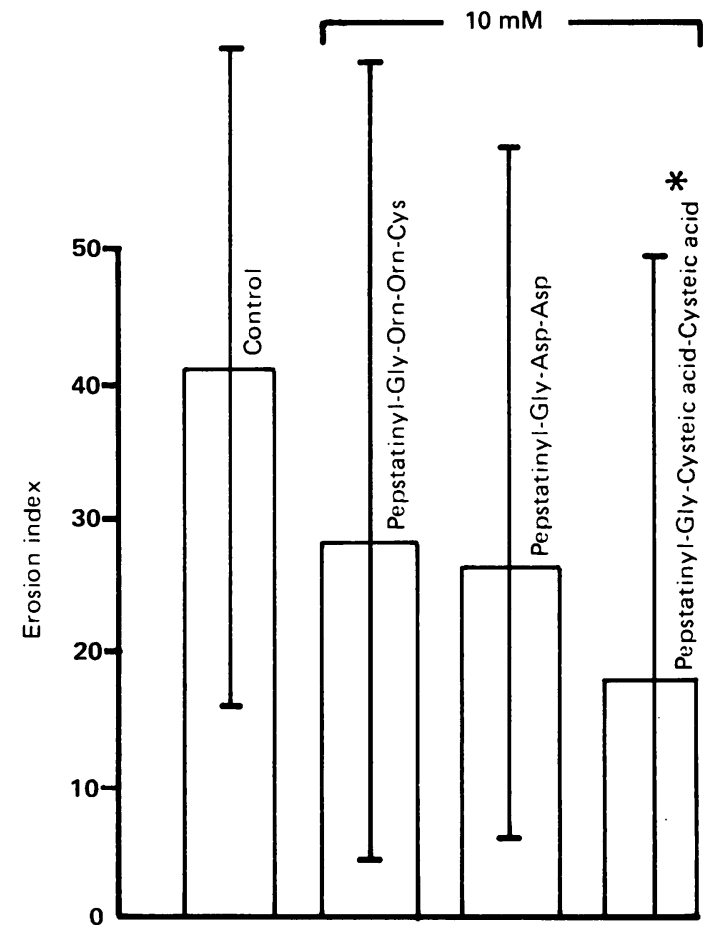

Fig. 3 Erosion index (mean) of groups of six rats receiving intravenous $P A F$ in the presence of intragastric $20 \%$ ethanol either alone or containing dissolved pepstatin analogue. Bars indicate the range of values obtained $\left({ }^{*}-p<0.05 \mathrm{v}\right.$ control).

pounds had a net positive charge which might interact with the net negatively charged mucus or allow the molecule to adhere to the negatively charged apical mucosal cell surface. Two compounds had a net negative charge which it was thought might target the molecule towards breaches in the mucosa where the positive charges of the basolateral mucosal cell membranes become exposed. Two compounds had sulphur containing groups which might interact with the disulphide bridges in the mucus and target the inhibitor to this layer.

The ability of the analogues to penetrate the mucus layer was investigated by measuring the tissue concentrations in different tissues two hours after intragastric administration in a pylorus ligated rat. After administration of a $20 \mathrm{mM}$ solution the concentrations achieved in the gastric mucosa were around 90 $\mathrm{pmol} / \mathrm{mg}$ wet weight of tissue. Ford et $a^{{ }^{11}}$ have shown that the total pepsin like proteinase content (which included zymogen) of rat gastric mucosa is approximately one quarter of this value indicating that the levels being achieved should be adequate to inhibit any accessible proteinase within the mucosa which becomes activated by a fall in mucosal $\mathrm{pH}$. 
There is no evidence from the observed tissue concentrations to support the concept that the negative charge or sulphur containing groups are targeting the inhibitors to the gastric mucus. Similarly there is no evidence to suggest that either a negative or a positive charge favours inhibitor concentration within the mucosa. The studies described do not, however, differentiate between different areas of the mucosa and it remains possible that the negatively charged analogues will be attracted to mucosal defects. This would clearly be a desirable property in an inhibitor of this kind.

The tissue distribution of Pepstatinyl-Gly-AspAsp was only measured after intragastric administration of a $1 \mathrm{mM}$ suspension because of its poor solubility (the solubility at $\mathrm{pH} 2$ was $0.8 \mathrm{mg} / \mathrm{ml}$ ) and therefore can not be directly compared with the other compounds. It does seem, however, that the mucosal concentration achieved by this compound was significantly higher than might be expected. A 20 fold reduction in the luminal concentration compared with the other analogues produced only a $50 \%$ reduction in the mucosal concentration. The concentrations of this analogue in bile, urine and serum are low suggesting that little inhibitor has passed through the mucosa into the blood stream, which implies that there might be some selective concentration within the mucosa. Aspartic acid is a weak acid and it is possible that this behaves in a similar manner to that proposed for the aspirin molecule in the stomach, being undissociated within the acid lumen and hence lipid soluble, passing through the cell wall into the mucosal cells where it ionizes in the physiological $\mathrm{pH}$ of the cytoplasm. If this is so then it is clearly a desirable property of such a compound.

All of the pepsin inhibitors which were tested in the controlled hypotension animal model at a $10 \mathrm{mM}$ intragastric concentration completely prevented the appearance of acute gastric erosions which were consistently seen in the control animals. In this model the hypotension probably causes a fall in mucosal $\mathrm{pH}$ as has been shown to occur in rabbits. ${ }^{16}$ This in turn catalyses the conversion of pepsinogen to active pepsin, which has previously been shown to occur in this situation. ${ }^{21}$ As there was no other difference between the control animals and those receiving the pepsin inhibitors, and the inhibitors are not known to have any action on the gastric mucosa other than the inhibition of aspartyl proteinases, it may be concluded that the protective effect upon the mucosa is the result of inhibition of aspartyl proteinase activity within the mucosa. This activity is likely to be pepsin although it is possible that lysosomal enzymes play a part. Cathepsin D is an aspartyl proteinase and should be inhibited by the pepstatin analogues as it is by native pepstatin. ${ }^{32}$ It would be of interest to directly measure the degree of inhibitor/enzyme binding within mucosal samples taken from these experimental animals. In practice, however, this is not possible as minute amounts of these extremely potent inhibitors contaminating or contained within the mucosa would render the results uninterpretable.

At the lower concentration there were few true superficial erosions but in some animals there were a number of intramucosal haemorrhages. It is not possible with the method used to measure tissue concentrations to detect changes in concentration of inhibitor across the thickness of mucosa. It is likely, however, that a concentration gradient of inhibitor exists from the gastric lumen at $1 \mathrm{mM}$ to the serum concentration at about $1 \mu \mathrm{M}$ and that it is the deeper layers of the mucosa which first suffer damage as the concentration of inhibitor becomes marginal.

The lesions seen at the lower inhibitor concentrations were predominantly intramucosal haemorrhages surrounded by a small area of necrosis. As the harmorrhage is trapped within the mucosa the size of the lesion will appear larger than the area of necrosis. The animals used in the controlled hypotension/ luminal acid model of erosions were heparinised in order to allow removal and retransfusion of blood and this may further accentuate these intramucosal microhaematomas.

Pepstatinyl-Gly-Cysteic acid-Cysteic acid which has a strong net negative change was the most effective of the inhibitors tested in this model. The effectiveness of this inhibitor was in contrast with its $\mathrm{Ki}$ value which was five-fold higher than the best compound at $\mathrm{pH} 2$. It has a very high aqueous solubility but this failed to produce an increase in the measured mucosal concentration. Pepstatinyl-Gly-Asp-Asp also does surprisingly well in the animal model despite its lower aqueous solubility. It is possible that these negatively charged compounds are being attracted to exposed positive charges on the basolateral mucosal cell membranes in the area of mucosal breaches. They may therefore be selectively targeted to the areas where the mucosal barrier is broken and where th $\mathrm{pH}$ fall is likely to be greatest.

The use of PAF to induce acute gastric erosions, as described by Rosam et al, ${ }^{29}$ provides an alternative animal model to the controlled hypotension/luminal acid system which avoids the use of added luminal acid. It has been proposed that PAF is a major factor in the clinical pathogenisis of acute gastric erosions induced by septicaemic shock..$^{29}$ Platelet activating factor has been detected in vivo in the blood of rats subjected to endotoxic shock in concentrations similar to those which were administered in the PAF animal model described.

Although the mechanism by which PAF damages the mucosa is not well understood it seems likely that 
this is through local vascular changes particularly local stasis and venocongestion. ${ }^{29} \mathrm{~A}$ fall in local blood flow to areas of the mucosa will inevitably reduce the ability of the mucosa to remove the protons which represent the normal back diffusion from the lumen. Mucus secretion and local bicarbonate secretion are likely to be reduced allowing an increased rate of proton back diffusion into the mucosa. Finally, the relative anoxia produced by the vascular changes will allow the accumulation of metabolites leading to a further local fall in mucosal $\mathrm{pH}$. If one or all of these factors act together to reduce the $\mathrm{pH}$ in an area of mucosa below 5 then pepsinogen activation may begin. Once this occurs the pepsin produced is likely to amplify local damage opening the flood gates for further influx of protons, further reducing the $\mathrm{pH}$.

The macroscopic and microscopic appearances of the lesions in the PAF model, and in particular the marked antral sparing were similar to those found in the controlled hypotension/luminal acid model previously used. The antral sparing further supports the concept that pepsinogen stores within the mucosa of the body and fundus of the stomach are involved in the pathogenisis of, or amplification of, mucosal damage by PAF.

Despite high interanimal variability, significant mucosal protection was again provided by Pepstatinyl-Gly-Cysteic acid-Cysteic acid in the PAF model providing further evidence that inhibition of mucosal aspartyl proteinases affords protection to the mucosa from damage arising in a range of clinical circumstances.

None of the experiments described investigate chronic ulceration although many of the factors which induce acute ulceration are also implicated in chronic ulceration. The presence of a chronic ulcer indicates a balance between aggressive and defensive mucosal forces. Despite this treatment of chronic ulcers by reduction of luminal acid requires a marked rise in $\mathrm{pH}$ before healing occurs. It will therefore be of great interest to see if adequate intramucosal pepsin inhibition will accelerate the healing of chronic peptic ulcers. The single clinical trial of pepstatin has shown no benefit despite good inhibition of luminal pepsin. ${ }^{27}$ It is likely that, as in the case of acute gastric erosions, the pepsin inhibitors need to be soluble in physiological media in order to gain access to the site of pepsin induced mucosal damage. This area warrants further study.

The protective effect of soluble pepstatin analogues has been shown in two animal models of acute gastric erosions which are believed to simulate the pathophysiology of erosions occurring clinically in hypotensive and endotoxic shock. At a $10 \mathrm{mM}$ intraluminal concentration all three pepstatin analogues tested completely abolished the appear- ance of acute gastric erosions in the controlled hypotension/luminal acid animal model.

This research was kindly supported by the British Technology Group and by the St George's Hospital Medical Research Committee.

\section{References}

1 Fogelman MJ, Garvey JM. Acute gastroduodenal ulceration incident to surgery and disease. Am J Surg 1966; 112: 651-6.

2 Lucas CE, Riddle J, Rosenberg B, Walt AJ. Natural history and surgical dilemma of stress gastric bleeding. Arch Surg 1971; 102: 266-73.

3 Skillman JJ, Bushnell LS, Goldman H, Silen W. Respiratory failure, hypotension, sepsis and jaundice. A clinical syndrome associated with lethal haemorrhage from acute stress ulceration of the stomach. Am J Surg 1969; 117: 523-30.

4 Beil AR, Mannix H, Beal JM. Massive upper gastrointestinal haemorrhage after operation. Am J Surg 1964; 108: 324-30.

5 Goodman AA, Frey CF. Massive upper gastrointestinal haemorrhage following surgical operations. Ann Surg 1968; 167: 180-4.

6 Cushing H. Peptic ulcers and the interbrain. Surg Gynecol Obstet 1932; 55: 1-34.

7 Kamada T, Fusamoto H, Kawano S, et al. Gastrointestinal bleeding following head injury. A clinical study of 433 cases. J Trauma 1977; 17 : 44-7.

8 Halloran LG, Zfass AM, Gayle WE, Wheeler CB, Miller CB, Miller JD. Prevention of acute gastrointestinal complications after severe head injury: A controlled trial of cimetidine prophylaxis. Am J Surg 1980; 139: 44-8.

9 Curling TB. Acute ulceration of the duodenum in cases of burns. Trans Med Chir Soc Lond 1842; 25: 260-81.

10 Czaja AJ, McAlhany JC, Pruitt BA. Acute gastroduodenal disease after thermal injury. $N$ Engl $J$ Med 1974; 291: 925-9.

11 Pruitt BA, Foley FD, Moncrief JA. Curlings ulcer: A clinicopathological study of 323 cases. Ann Surg 1970; 172: 523-39.

12 Martin LF, Stalock DK, Simonowitz DA. Failure of cimetidine prophylaxis in the critically ill. Arch Surg 1979; 114: 492-6.

13 Priebe HJ, Skillman JJ, Bushnell LS, Long PC, Silen W. Antacid versus cimetidine in preventing acute gastrointestinal bleeding. $N$ Engl J Med 1980; 302: 426-30.

14 Stothert JC, Simonowitz, Patchen Dellinger E, et al. Randomised prospective evaluation of cimetidine and antacid control of gastric $\mathrm{pH}$ in the critically ill. Ann Surg 1980; 192: 169-74.

15 Kivilaakso E, Silen W. Pathogenisis of experimental gastric mucosal injury. N Engl J Med 1979; 301: 364-9.

16 Kivilaakso E, Fromm D, Silen W. Relationship between ulceration and intramucosal $\mathrm{pH}$ of gastric mucosa during haemorrhagic shock. Surgery 1978; 84: 70-8.

17 Alphin RS, Vokal VA, Gregory RL, Bolton PM, Tawes 
JW. Role of intragastric pressure, $\mathrm{pH}$ and pepsin in acute gastric ulceration in the rat. Gastroenterology 1977; 73: 495-500.

18 Mangala JC, Kim YM, Turner MD. Are pepsinogens activated in gastric mucosa after aspirin induced injury. Experimentia 1974; 30: 727-9.

19 Ohe K, Veno N, Yokaya H, Miyoshi A. The activation of pepsinogen inside the gastric mucosa caused by the hydrogen ion back diffusion during the course of aspirin ulceration. Hiroshima J Med Sci 1979; 28: 1-11.

20 Ohe K, Yokaya H, Kitaura T, Kunita T, Miyoshi A. Increase in pepsin content in gastric mucosa during the course of aspirin and taurocholate induced gastric ulceration in rats. Dig Dis Sci 1980; 25: 849-56.

21 Ford TF, Grant DAW, Austen BM, Hermon-Taylor J. Intramucosal activation of pepsinogens in the pathogenisis of acute gastric erosions and their prevention by the potent semi-synthetic amphipathic inhibitor pepstatinyl-glysyl-lysyl-lysine. Clin Chim Acta 1985; 145: 37-47.

22 Bianchi RG, Cook DL. Antipepsin and antiulcerogenic properties of a synthetic sulphated polysaccaride (SN263). Gastroenterology 1964; 47: 409-14.

23 Anderson W, Soman PD. Degraded carrageenan and experimental acute gastric ulceration in the guinea pig. Nature 1963; 199: 389.

24 Zimmon DS, Miller G, Cox G, Tesler MA. Specific inhibition of gastric pepsin in the treatment of gastric ulcer. Gastroenterology 1969; 56: 19-23.

25 Baron JH, Gribble RJN, Holdstock DJ, Misiewicz JJ. Double blind controlled trial of amylopectin sulphate (Depepsin) in the symptomatic treatment of duodenal ulcer. Gut 1977; 18: 723-4.

26 Umezawa H, Aoyagi T, Morishima H. Pepstatin, a new pepsin inhibitor produced by actinomycetes. $J$ Antibiot 1970; 23: 259-62.

27 Bonnevie O, Svendsen LB, Holst-Christiansen J, Staehr Johansen T, Soltoft J, Christiansen PM. Double blind randomised clinical trial of a pepsin inhibitory pentapeptide (pepstatin) in the treatment of duodenal ulcer. Gut 1979; 20: 624-8.

28 Umezawa $\mathbf{H}$. Structures and activities of protease inhibitors of microbial origin. Methods Enzymol 1976; 45: 678-97.

29 Rosam AC, Wallace JL, Whittle BJR. Potent ulcerogenic actions of platelet activating factor on the stomach. Nature 1986; 319: 54-6.

30 Huddy SPJ. Cambridge University: M Chir Thesis 1987.

31 Ford TF, Hermon-Taylor J, Grant DAW. A sensitive fluorometric assay for the simultaneous estimation of pepsin and pepsinogen in gastric mucosa. Clin Chim Acta 1982; 126: 17-23.

32 Aoyagi T, Morishima $\mathrm{H}$, Nishizawa R, Kunimoto $\mathrm{S}$, Takeuchi $T$, Umezawa $H$. Biological activity of pepstatins, pepstatone $\mathrm{A}$ and partial peptides on pepsin, cathepsin D and renin. J Antibiot 1972; 25: 689-94. 